\title{
LEARNING THE PRAGMATICS OF 'SUCCESSFUL' IMPRESSION MANAGEMENT IN CROSS-CULTURAL INTERVIEWS ${ }^{1}$
}

\author{
Grahame T. Bilbow and Sylvester Yeung
}
'O wad some Pow'r the giftie gie us
To see oursels as others see us! It wad frae mony a blunder free us, and foolish notion.' (To a louse, Robert Burns (1759 - 1796)

\section{Introduction}

In work environments, people commonly seek to convey a variety of impressions of themselves to their colleagues, superiors and subordinates through their spoken discourse. These include impressions of "authority", "likeability", "respectfulness" and a wide range of other common impressions that are considered "positive". Relatively little is known, however, about how, in discoursal terms, such impressions are successfully projected either in monocultural or in cross-cultural contexts.

This paper reports on a study that has been conducted at the Hong Kong Polytechnic University, which has sought to address the issue of how interpersonal impressions are mediated through spoken discourse in monocultural and cross-cultural encounters. Central to the study is the social psychological construct of 'impression management' elaborated by Goffman (1959), in The Presentation of Self in Everyday Life.

Specifically, the study focuses on the impressions students project of themselves in the course of interviews for positions in the hotel industry. Of particular interest are those features of students' performance that can cause problems for impression management, especially when interviewer and interviewee come from different cultural groups, as is often the case in the pluralistic society of Hong Kong.

\footnotetext{
${ }^{1}$ This research was generously supported by funding from the Hong Kong Polytechnic University (Project account number 0351644 A3 710 entitled “A Study of Intercultural Impression Management in Employment Interviews")
} 


\section{Impression management}

"Impression management" is a social psychological phenomenon that has been the subject of a considerable body of research since the term was coined in 1959 by Erving Goffman in The Presentation of Self in Everyday Life (see for example Bilbow (1996, 1997); Cody and McLaughlin (1990); Gardner and Martinko (1988); Gardner, Peluchette and Clinebell (1994); Giacalone and Rosenfeld (1989, 1991); Leary and Kowalski (1990); Leary (1996); Tedeschi and Melburg (1984); Tedeschi (1981); and Wayne and Kacmar (1991)).

According to Goffman, impression management is a matter of "the way in which the individual ... presents himself and his activity to others, the ways in which he guides and controls the impression they form of him, and the kinds of things he may and may not do while sustaining his performance before them" (Goffman 1959: preface).

Goffman's dramaturgical use of the term "impression management" tends to focus on people's conscious and "frontstage" attempts to manage impressions of themselves through the use of 'props' and strategies, rather than on impression management as an unconscious and unplanned process. However, more recent research has tended to view impression management as consisting of both conscious and unconscious activity. For example, Schlenker and Weigold (1992) state that impression management is a matter of those activities whereby "people attempt to regulate and control, sometimes consciously and sometimes without awareness, information they present to audiences, particularly imformation about themselves" (Schlenker and Weigold 1992: 134). Similarly, Bilbow (1996), in his study of the relationship between spoken discourse and impression management in business meetings, describes impression management-related discourse as "those language behaviours, intentional or unintentional, that create and maintain impressions, with or without a conscious purpose." (Bilbow 1996: 4)

Impression management is a two-part phenomenon that involves (i) the individual performing in particular ways, and (ii) an audience reacting in particular ways to the individual's performance. We can term these processes "projection" and "attribution" respectively (Bilbow 1996: 66). Impression management can be broadly "resonant" or "discordant" ("congruent" or "incongruent" in Gardner et al's (1994) terms). In impression management that is resonant, the impression attributed by the hearer parallels the impression the speaker believes him/herself to be projecting. In other words, the speaker's interlocutor perceives the speaker in ways that match the speaker's preferred image. In impression management that is discordant, on the other hand, the impression formed by the hearer is at odds with the speaker's preferred image.

In cross-cultural encounters, the potential for discordant impression management seems to be far greater than in monocultural encounters. Here, the term "cross-cultural encounter" is taken to mean any encounter between two or more people who, in any particular domain, do not share a common linguistic or 'cultural' background. This might include workers and management, members of ethnic minorities and the police, or (when the domain of discourse is academic writing) university lecturers and new undergraduate students (Thomas 1983: 92). In other words, in encounters where interlocutors do not share a common cultural background, the potential for mismanaged impressions and crossed wires appears to be considerably greater than in encounters where interlocutors have a similar cultural background (Bilbow 1996: 2). 


\section{Impression management in placement interviews}

As was mentioned above, in most forms of social interaction, people do not give too much thought either to the form of their own spoken discourse (projection) or to its possible impact on other interactants (attribution). They do not set out to create specific impressions; rather, impressions are formed as a by-product of interaction. In the interview setting, however, it is quite common for impressions to be consciously managed, or 'stage' managed, and interviews provide an ideal opportunity for studying conscious strategic impression management. Cross-cultural interviews also provide an opportunity to investigate the possible relationship between impression management and pragmatic failure, since it appears likely that pragmatic failure may come about partly because of the unintended impressions that arise when members of different cultural communities interact.

For example, pragmalinguistic errors occur when non-native speakers inadvertently use language forms which are normally associated with a community of which they are not a part (Thomas 1984). Such errors in the context of an interview may include using extreme linguistic directness to express personal wishes, disagreement, and so on, in cultural contexts in which this is considered inappropriate. It can be argued that the salience of such pragmalinguistic errors lies in the fact that they tend to result in the formation of negative (ie discordant) impressions of a type that may disrupt further communication.

Thomas' other category of pragmatic error, sociopragmatic errors, also appears to affect interpersonal impression management in interviews. Sociopragmatic errors occur when there is a mismatch between what speakers perceive to be appropriate linguistic behaviour. Examples of sociopragmatic failure listed by Thomas (1984) include mismatches in the size of imposition of speech acts (eg what would be an acceptable request or offer), references to taboo subjects, and value judgments. In the context of an interview, sociopragmatic failure may occur when a candidate fails to self-disclose in a situation where self-discolure is expected, for example, or offers intimate personal details or opinions when such behaviour is not expected. Once again, the salience of sociopragmatic errors lies in the fact that they may adversely affect how speakers perceive each other and the "labels" they attach to each other.

\section{The data}

The first phase of data collection for this study took place in May 1997. A total of eleven placement interviews attended by second year students from the Hong Kong Polytechnic University's Bachelor of Arts degree in Hotel \& Catering Management programme were videorecorded. Students, interviewers and the hotels involved gave their consent for data collection.

The function of these interviews was to select students for a three-month job placement during the summer vacation between the second and third year of their studies. Although these were not particularly 'high-stakes' gate-keeping encounters (Erickson 1976), there was no evidence to suggest that students took them lightly.

Each student was interviewed in situ at one of the range of hotels that participate in the placement scheme. These range from five-star hotels in central Hong Kong to threestar hotels in more distant locations. Interviews were conducted either by the human 
resources manager of the hotel or by the manager responsible for the operational area in which the student would be placed, for example the restaurant manager; the front office manager; the rooms manager. Generally, human resources managers were local Cantonesespeaking Chinese, while operations managers were native or non-native English-speaking Western expatriates (from Australia, America or Europe).

In the second phase of the study conducted in June 1997, one-to-one follow-up interviews were conducted with each of the interviewers (in English) and with each of the students (in Cantonese, the local Chinese dialect) ${ }^{2}$. During these separate interviews, interviewer and student were asked to watch their interview again, and to talk it through, making observations on the student's performance. This was done so as to produce talkthrough protocols on the basis of 'metapragmatic assessments' (Kasper \& Dahl 1991) of the student's on-going discourse from both the interviewer's and the student's perspective.

This methodology was particularly relevant given the hermeneutic nature of judgments of impression management. According to Kasper \& Dahl (1991), participantobservers' metapragmatic assessments can "provide an important corrective, or confirmation, of the values and weights of contextual factors built into the instrument by the researcher" (Kasper \& Dahl 1991: 238). As they point out, "the combination of production and metapragmatic assessment data provides an empirical basis for explaining observed patterns of speech act realization and politeness in terms of perceived contextual constraints, and of the pragmatic force and politeness value language users attribute to different linguistic means and strategies." (Kasper \& Dahl 1991: 238)

It emerged that all of the placement interviews consisted of very similar phases, despite the fact that they were conducted by different interviewers at different hotels. Placement interviews usually had the following eight-phase structure:

(i) self-introduction of the candidate, eg:

"So tell me about yourself...";

(ii) favourite subjects at University, eg:

"What is your favourite subject?";

(iii) background knowledge of the hotel, eg:

"What do you know about our hotel?";

(iv) reasons for choice of the hotel industry as a career, eg:

"Why did you choose the hotel industry?";

(v) possible career plan, eg:

"Where do you see yourself in two years' time?";

\footnotetext{
${ }^{2}$ Most managerial staff in the hotel industry in Hong Kong are reasonably proficient in English. The fact of interviewing them in English did not cause any difficulties, and they were quite capable of expressing their personal reacitons. However, students were interviewed in Cantonese because, in some cases, their poor command of English might have restricted their ability to express themselves.
} 
(vi) the purpose of the placement, eg:

"The purpose of the placement is so that you can develop ...";

(vii) roleplays, eg:

"How would you greet a guest in English?; How would you take an order?"; etc;

(viii) negotiation over the specific department to work in, eg:

"Where specifically would you like to receive training?".

This last phase is one of the most interesting phases in terms of how students manage impressions of themselves. Commonly, in this negotiated phase, students ask if they can be placed in the Front Office of the hotel where they are to be working. This department is commonly perceived by students to be a pleasant one in which to work as it involves considerably less physical work than other departments. However, as the department is highly visible, and seldom has vacancies, hotel managers tend to prefer not to place students in the Front Office. Almost invariably, therefore, students are told that it is not possible for them to work at the front desk, and an alternative is offered. This usually involves working in the Food and Beverage Department as a waiter or waitress in one of the hotel's restaurants.

Given their generally negative perception of this type of work, students are seldom keen to accept the suggested alternative. As a result, a delicate negotiation commonly follows, in which students try to reach a compromise over the amount of time they will spend working in the Food and Beverage Department. Most commonly, students do this by arguing that their interests or strengths lie elsewhere. It is not surprising that, in this process of negotiation, it is important for students to choose their words with care so as not to damage impressions established in earlier phases of the interview.

\section{A sample negotiation}

The following is a short extract from the negotiation phase of one of the interviews videorecorded as part of the study ${ }^{3}$. In it, the interviewer is a male native English-speaking Canadian; the interviewee is a female Cantonese-speaking Chinese student.

\footnotetext{
Int: Let's talk about now the er (2) the programme itself $\{S: m m\}$ that you want to come on board for 16 weeks and work in the hotel er what do you think is (1) the best way to approach that. Er, do you want (2) what do you want to do? Do you want to gain exposure in all the different outlets working a week here a week here a week here understanding that you'd only be skimming the surface if you only spend a week in one particular area or would you rather spend your whole time in one area and learn as much about that as possible.

S: $\quad$ You mean in the F\&B outlet?
}

\footnotetext{
${ }^{3}$ The notation conventions used in this transcription are as follows: the numbers in round brackets indicate pauses in units of $1 / 2$ second; back channel comments are indicated in curly brackets; double round brackets are used to note paralinguistic features, such as nods and smiles.
} 
Int: Well, for example in $\mathrm{F} \& \mathrm{~B}\{\mathrm{~S}:$ ahha $\}$ or sales and marketing erm or reception

I'm not sure if we right now to be honest er if we are looking for somebody in the Rooms side $\{\mathrm{S}: \mathrm{mm}\}$ I am fairly certain that there we're more concerned now with getting some er good trainees in the Food and Beverage outlets $\{\mathrm{S}$ : $\mathrm{mm}\}$ but that that's flexible $\{\mathrm{S}: \mathrm{mm}(($ nods $))\}$ and we can still you know talk about that if that's where you want to go. It sounds like you you are more interested in going into the Rooms side, is that right? To reception?

S: $\quad$ Yes and also the Sales and Marketing but I don't mind working in the F\&B outlets. But I I want to (2) I can er have er different experience in different departments.

Int: Right.

S: $\quad$ So (2) I think maybe 2 or 3 departments I can work within this 16 months is is pretty good for me

Int: Yea. I think that er 22 departments would probably be the maximum that we put you in. \{S: $\mathrm{mm}(($ nods $))\}$ If you went in 3 departments over 16 weeks about 5 weeks per department you you'd learn you'd begin to learn and just as your you reach a point where you can really contribute in a positive fashion $\{\mathrm{S}$ : ((nods)) $\}$ to the department, you'd be pulled out $\{$ S: ((smiles)) $\}$ and you'd go to another department and you'd have to learn everything all over again \{S: ((nods and smiles)) \} so it's a kind of a (2) it's a bit of a give and take. We want you to learn as much as possible but we also want you to get to a point where you can also contribute $\{\mathrm{S}: \mathrm{mm}\}$ and the more interaction that you have with the guest the better off you know your learning experience $\{\mathrm{S}:(($ nods $))\}$ will be in total so that's why it's best to er maybe work in one outlet or two $\{\mathrm{S}: \mathrm{mm}(($ nods $))\}$ at most and then you can really become efficient and know the job $\{\mathrm{S}:(($ nods $))\}$ and become you know quite skilled in that one area

S: $\quad$ Mm. yes that's fine. Maybe two departments is okay.

Int: Yea okay erm so that decision erm we can talk about that erm you know at a later time once we've gone through the interview process. \{S: mm ((nods)) \} about where we'll put you. But er if it was in a Food and Beverage outlet, that would that be okay with you?

S: $\quad$ Yes ((nods)) yes (4) ((smiles)) but it doesn't matter I work in the Food and Beverage outlet but erm it's better for me to work in other departments maybe ((smiles)) I just make a suggestion 2 months Food and Beverage or 2 months other departments

Int: $\quad$ Sure. Yea. That's a good idea.

S: $\quad$ Yea

\section{Analysis}

As mentioned in the methodology described above, the interviewer and student in this negotiation were interviewed in separate follow-up interviews in order to allow collection of their 'metapragmatic assessments' of certain aspects of their behaviour in the initial interview. Follow-up interviews were semi-structured and largely controlled by the interviewees themselves, who were asked to talk through the videorecording of their initial interview. These observations were then recorded and summarised.

When asked what type of impression was a 'positive' one for a student to project in a placement interview, the interviewer and the student in this extract shared a common view. They both agreed that, ideally, the student should come across as 'respectful' yet 'assertive'. When asked whether they thought that the student's performance in the interview had achieved this impression, both felt that the student had managed, broadly 
speaking, to straddle this difficult line in a convincing way. Aspects of the student's performance that were mentioned as having contributed to the creation of this positive impression included the following:

(i) The student's use of an appropriate range of speech acts:

(a) Clarification

eg "You mean in a F\&B outlet?" (line 8)

(b) Assertion

eg "I want to (2) I can er have er different experience in different departments." (lines 17-18)

(c) Suggestion

eg "So (2) I think maybe 2 or 3 departments I can work within this 16 months is is pretty good for me." (lines 20-21)

(d) Negotiation

eg "Yes ((nods)) yes (4) ((smiles)) but it doesn't matter I work in the Food and Beverage outlet but erm it's better for me to work in other departments maybe." (lines 40-41)

(ii) The student's use of disarming supportive moves (Blum-Kulka et al 1989: 287) when making assertions. These showed appropriate respect for the interviewer:

(a) "I don't mind working in the F\&B outlet. But I want ..., I can have different experience in different departments." (lines 16-17)

(b) "It doesn't matter I work in the Food and Beverage outlet, but er (pause) it's better for me to work in other departments, maybe." (lines 40-41)

(iii) The student's use of hedges when making suggestions. These were felt to be sufficiently and genuinely deferential:

(a) "I just make a suggestion, it's two months in Food and Beverage or two months other departments." (line 42)

(b) downtoners, eg "maybe", "just", "pretty good", "I think".

(c) occasional repair strategies, eg "But I want ..., I can have different experience in different departments." (lines 16-17)

(iv) The student's suggestion that she and he shared a common goal/ perspective, which was partly achieved through the use of parallelism of the following type:

Int: $\quad$ "That's why it's best to er maybe work in one outlet or two at most." (line 
32)

S: $\quad$ "... it's better for me to work in other departments, maybe." (line 41)

(v) The student's use of paralinguistic features, which were judged to be appropriate to creating an impression of respectfulness and assertiveness. For example, she nodded and gave back channel comments to signal assent (e.g. lines 12-13; 23, 2527 , etc); the interviewer felt that her generally serious facial expression indicated that serious thought was being given to seeking a mutually beneficial solution as equals. Her occasional smiles were viewed by the interviewer as indicating comprehension and openness (e.g. lines 26,28$)$ rather than amusement.

(vi) The student's use (and control) of prosodic features, such as:

(a) a rising rather than falling intonation contour for checking understanding of the interviewer's questions;

(b) avoidance of heavy stress to voice either strong agreement or disagreement;

(c) good timing, which was felt to be appropriate to the creation of an impression of independent thought and respectfulness. For example, there were no situationally inappropriate interventions or outbursts, even when the student wanted to voice considerable disagreement.

Interestingly, the interviewer felt that, on occasions, the student's slightly negative reaction to working in one of the hotel's restaurants had bordered on being disrespectful. He commented that if he had been a local Chinese interviewer it might have been more appropriate for her to have kept this reaction to herself. However, he felt that she had demonstrated enough respect for him to keep her overall impression positive. In sum, she had come across as a student who was assertive and yet respectful of the interviewer's authority.

The student also felt that she had come across positively, although she too questioned whether she had shown sufficient respect for the interviewer. In her words, "I think the part when I insisted too much (see negotiation above), I have some doubts about whether I was respectful enough to the interviewer. But I just wanted to put my point across, and then I thought he was a foreigner, so maybe he wouldn't mind. After all, the interviewer didn't lose face". This last point suggests that the student used her awareness of pragmatic differences across cultures to good effect, and succeeded in projecting a positive impression by acting in a strategically appropriate way.

To summarise, in this extract, the student succeeded in creating a positive impression in the mind of the interviewer by balancing "assertiveness" with "respectfulness" through the use of certain lexico-grammatical, prosodic and paralinguistic features. Her specific choice of strategies was significantly affected by (i) the fact that her interlocutor was a Canadian, and (ii) her suspicion (that proved correct) that he was less likely to be face-oriented than a local Chinese interviewer. 


\section{Summary of findings}

Analysis of the entire range of interviews yields a complex picture. The following is a brief summary of the range of features of verbal and non-verbal behaviour that those interviewed mentioned as having a significant impact on the impressions that students created. Clearly, metapragmatic assessments of this type cannot constitute an exhaustive list. This is especially so given the extremely limited data set used:

(i) Aspects of students' discourse. Specifically:

(a) relevance (including the quantity, clarity and explicitness of content, as well as the level and form of self-disclosure);

(b) organisation of ideas (including the 'logical' sequencing of ideas);

(c) cohesion and coherence (inclding the fluency of the speakers and what was frequently referred to as their 'smoothness');

(d) tone and register (including their level of positivity, their level of encoded politeness, their directness, face-giving and situational appropriateness ( or "dai fong tak tai"4);

(e) personal stance (including the level of solidarity they demonstrate with the interviewer, and their demonstration of conformity);

(f) conversational management strategies (including their adherence to conventions of turn-taking, interruptions and back channel).

(ii) Prosodic features of students' discourse. Specifically:

(a) particular intonational contours were commonly associated with the creation of "sympathetic", "positive" or "helpful" impressions, while others, specifically the low-fall contour, appeared to be associated with "negative" or "unhelpful" impressions

(b) speed of talk appeared to affect the impressions formed by interviewers, as did paralinguistic features, such as giggling (which, according to some interviewers, created an impression of "immaturity").

(iii) Aspects of students' non-verbal behaviour. Specifically:

(a) facial expressions (eg smiles and frowns) seemed to lead to the creation of particular impressions (eg openness, sincerity, cooperativeness, and so) on;

\footnotetext{
${ }^{4}$ This term is used to describe an important form of situational appropriateness common in Chinese social life, which includes notions of respect and face-giving.
} 
(b) gestures and body posture appeared to be associated with the creation of particular impressions (eg sobriety, expressiveness, extroversion, interest, and so on);

(c) other non-verbal aspects of communication, eg dress, cleanliness, and physical attractiveness.

\section{Discussion}

The cultural background of the interviewer appeared to be a major factor affecting how aspects of interviewees' performance were perceived and interpreted. Interviewers with different cultural backgrounds appeared to foreground particular communicative strategies. For example, Chinese interviewers in the corpus tended to foreground indirectness, and therefore tolerated more circumlocution on the part of interviewees than did Western interviewers, although neither group appeared to value longwindedness. Chinese interviewers also tended to foreground respectfulness, and expected more evidence of facegiving than did Western interviewers, although, once again, neither Chinese nor Western interviewers appeared to expect students to be self-denigrating or ingratiating.

Conversely, Western interviewers tended to foreground self-disclosure and explicitness, whereby interviewees were expected to lay bare their personal experience and feelings. Several Western interviewers commented that the very purpose of the interview was to allow the interviewer to "get to know" the student's personal interests, motivations and feelings, and to find out about the student's family background. In contrast, Chinese interviewers tended to expect interviewees to maintain considerable distance and did not actively encourage intimate self-disclosure on the part of students.

Analysis of the interviews with the interviewers reveals that Chinese and Western interviewers tended to expect different things from the people they interviewed, and negatively evaluated features of interviewees' performances that did not conform to these expectations.

The following table shows the personality/ behavioural traits that Chinese and Western interviewers expected candidates to display:

\begin{tabular}{|c|c|c|}
\hline & Chinese expectations & Western expectations \\
\hline Positive & $\begin{array}{ll}\text { - } & \text { Conservative } \\
\text { - } & \text { Courteous } \\
\text { - } & \text { Sincere } \\
\text { - } & \text { Respectful } \\
\text { - } & \text { Smiling }\end{array}$ & $\begin{array}{ll}\text { - } & \text { Confident } \\
\text { - } & \text { Positive } \\
\text { - } & \text { Spontaneous } \\
\text { - } & \text { Expressive } \\
\end{array}$ \\
\hline Negative & $\begin{array}{ll}\text { - } & \text { Flamboyant } \\
\text { - } & \text { Slovenly }\end{array}$ & $\begin{array}{ll}\text { - } & \text { Nervous } \\
\text { - } & \text { Vague }\end{array}$ \\
\hline
\end{tabular}

A further short extract, this time from an interview between a Chinese male interviewer and a Chinese female student, will illustrate the effect of conflicting expectations and exemplify discordant impression management. In this extract, it was the student's "over-expressive" 
non-verbal behaviour that damaged her impression management and led the interviewer to perceive her as immature and inappropriate for the position.



It is interesting to note that, when asked why she had sneered (line 3), the student responded that she had wanted to show the interviewer that she thought that practical experience of the type she would be gaining was more valuable than theoretical knowledge of the type taught at the University (in line with what she assumed to be the interviewer's point of view). When asked why she had giggled (line 12), she responded that she was just trying to be pleasant by reacting in a "human" way to the fact that the interviewer had eaten at the University's practice restaurant (in line with how she assumed the interviewer wanted her to behave). In both cases, she felt that she had come across in an appropriately expressive and "human" way. However, in both cases, the interviewer felt she had acted inappropriately.

Both of the interviews commented on above are "cross-cultural" encounters. In the first interview, interviewer and interviewee came from different ethnic backgrounds, while, in the second, interviewer and interviewee came from different occupational and generational backgrounds. In such cross-cultural encounters, we have seen that differences in interviewer/interviewee expectations can affect interpersonal impression management and sometimes lead to pragmatic failure. In the corpus collected in this study, for example, indirect discourse was sometimes negatively interpreted by Western interviewers as symptomatic of wooliness, lack of comprehension or lack of ideas; self-disclosure was sometimes viewed by Chinese interviewers as evidence of self-aggrandisement or psychological instability; and expressive behaviour by young candidates was sometimes perceived by older, managerial-level interviewers as symptomatic of their being immature and/or nervous.

\section{Implications for teaching and learning}

This study has been motivated by the belief that greater intercultural sensitivity goes hand in hand with a better understanding of the pragmatics of interpersonal discourse processes. If students' awareness in each of these areas can be developed, not only their job-getting skills but also their wider communication skills will be enhanced.

For the students involved in this study, it is hoped that their involvement has been 
a learning process in itself. Asking students to introspect on their own and others' verbal and non-verbal behaviours during interviews may have some impact on their awareness of the complex relationship between spoken discourse and impression management, and their understanding of the effect of their discourse on others' perceptions of them. It remains to be seen whether such perceptual changes, if they have occurred, are short-lived, or whether they will remain with students in the longer term.

It is also anticipated that the data and analytical findings generated by this study will be useful for helping a wider range of students perform better in interviews. 'Better' performance clearly means more than the mere parotting of prescribed forms of discourse. It is hoped that, through the process of learning, students can become more reflective, enlightened and capable of making pragmatically aware judgments about the appropriacy of their behaviour on the basis of a better understanding of the consequences the words they use have on others. At the moment, there are plans to use the results of this study in two ways:

(i) Revision of second year undergraduate students' syllabus materials to include authentic video input, and the creation of tasks based on this video input to practise certain pragmatically salient aspects of discourse, for example:

(a) Directness: For example, varying the directness of assertions and suggestions by using hedges, disarming supportive moves, and so on;

(b) Conversational management: For example, practising good timing; making good use of silence; interrupting interviewers appropriately; making 'positive' back channel comments, and so on;

(c) Prosodic and paralinguistic features : For example, using appropriate intonational contours in assertions and suggestions to demonstrate and maintain interest; controlling speed of talk to increase comprehensibility and demonstrate affect; avoiding inappropriate paralinguistic features, and so on.

(ii) In the longer-term, it is hoped that interactive CD-ROM-based self-access materials will be created which will focus on the relationship between spoken discourse and the management of impressions in intra- and inter-cultural contexts.

\section{References}

Bilbow, G.T. (1996) Managing impressions in the multicultural workplace: An impression management-based model for cross-cultural discourse analysis and awareness training for the workplace. Unpublished Ph.D. thesis, Hong Kong: City University of Hong Kong.

Bilbow, G.T. (1997) Spoken discourse in the multicultural workplace in Hong Kong: Applying a model of discourse as 'impression management'. In F. Bargiela-Chiappini and S. Harris (eds.), The languages of business: an international perspective. Edinburgh: Edinburgh University Press, pp. 21-48. 
Blum-Kulka, S., J. House, \& G. Kasper (eds.) (1989) Cross-cultural pragmatics: Requests and apologies. Norwood, NJ: Ablex.

Cody, M.J. \& M.L. McLaughlin (eds.) (1990) The psychology of tactical communication. (Monographs in social psychology of language, 2). Clevedon: Multilingual Matters.

Erickson, F. (1976) Gate-keeping encounters: a social selection process. In P. Sanday (ed.), Anthropology and the public interest: Fieldwork and theory. New York: Academic Press.

Gardner, W.L. \& M.J. Martinko (1988) Impression management: An observational study linking audience characteristics with verbal presentations. Academy of Management Journal 31: 42-65.

Gardner, W., L. Peluchette, J. Van Eck \& S.K. Clinebell (1994) Valuing women in management: An impression management perspective of gender diversity. Management Communication Quarterly 8.2: 115164 ;

Giacalone, R.A. \& P. Rosenfeld (eds.) (1989) Impression management in the organization. Hillsdale, NJ: Erlbaum.

Giacalone, R.A. \& P. Rosenfeld (eds.) (1991) Applied impression management. London: Sage.

Goffman, E. (1959) The presentation of self in everyday life. Garden City, NY: Doubleday.

Kasper, G. \& M. Dahl (1991) Research methods in interlanguage pragmatics. Studies in Second Language Acquisition 13: 215-247.

Leary, M.R. (1996) Self-presentation: Impression management and interpersonal behavior . Boulder, Colorado: Westview Press.

Leary, M.R. \& R.M. Kowalski (1990) Impression management: A literature review and two-component model. Psychological Bulletin 107.1: 34-47.

Tedeschi, J.T. (ed.) (1981) Impression management theory and social psychological research. New York: Academic press.

Tedeschi, J.T. \& V. Melburg (1984) Impression management and influence in organizations. Research in Sociology of Organizations 3: 31-58.

Thomas, J. (1983) Cross-cultural pragmatic failure. Applied Linguistics 4.2: 91-112.

Thomas, J. (1984) Cross-cultural discourse as 'unequal encounter': Towards a pragmatic analysis. Applied Linguistics 5.3: 226-235.

Wayne, S.J. \& K.M. Kacmar (1991) The effects of impression management on the performance appraisal process. Organizational Behavior and Human Decision Processes 48: 70-88. 